\title{
A CASE REPORT: ANAESTHETIC MANAGEMENT OF A CUT THROAT INJURY
}

Shruthi Jayaram ${ }^{1}$, Bhagyashree Amingad ${ }^{2}$

\section{HOW TO CITE THIS ARTICLE:}

Shruthi Jayaram, Bhagyashree Amingad. "A Case Report: Anesthetic Management of a Cut Throat Injury". Journal of Evolution of Medical and Dental Sciences 2014; Vol. 3, Issue 60, November 10; Page: 13487-13489, DOI: $10.14260 /$ jemds/2014/3800

ABSTRACT: Cut throat injuries are regarded as fatal injuries, as there is high chances of injury to vital structures of the neck. Patients may present with acute blood loss due to injury to major vessels, airway compromise, aspiration. Early intervention could save patients life in majority of cases. We hereby report a case of suicidal cut throat injury and its anesthetic management.

KEYWORDS: Suicide, cut throat injury, self-inflicted.

INTRODUCTION: Suicide is one of the 10 leading causes of death in the world. Familial troubles, psychiatric illness and poverty are the triggering factor in suicidal attempt. ${ }^{1}$ Globally, cut throat injuries accounts for approximately 5\%-10\% of all traumatic injuries with multiple structures being injured in $30 \%$ of patients. ${ }^{2}$ It has been observed that suicidal cut throat injuries is rare in India. ${ }^{3}$

Their initial management is straight forward and involves establishing an airway either via endotracheal tube or tracheostomy and then surgical repair of the transacted tissue. This may follow wound debridement if the wound is infected and surgical repair is fraught with laryngo-tracheal stenosis which can be a long term morbidity suffered by patients. ${ }^{4,5}$

Cut throat injuries with suicide as the motivating factor usually require rapid and interdisciplinary treatment. ${ }^{6}$ The anaesthesiologist and psychiatrist working in conjunction with the otolaryngologist should manage these patients.

CASE REPORT: A 40 year old male was brought to emergency unit with self-inflected cut throat using a shaving razor blade at Hassan institute of medical sciences. on admission at emergency room patient was well oriented, agitated, and restless but not in respiratory distress. Air blast was present from cut open wound. Vitals were pulse $128 / \mathrm{min}$, blood pressure $80 / 60 \mathrm{~mm}$ of $\mathrm{Hg}$ and $\mathrm{spo}_{2} 100 \%$ in room air,he was in hypovolemic state. . Immediately we secured two wide bore cannulas of 16G, blood sample was sent for grouping and cross matching and for $\mathrm{Hb} \%$ estimation. crystalloids were started and the patient was immediately shifted to operation theatre (OT) for emergency exploration and haemostasis.

in the OT, patient was monitored with multi parameter monitoring- ECG, Pulse oxymeter, NIBP. On exploration by the ENT surgeon, the wound was found at the level of thyroid cartilage. A cuffed endotracheal tube of $7 \mathrm{mmID}$, was placed through the open end of the trachea under aseptic precautions and the airway was secured. For further management general anesthesia was required. We induced the patient with thiopentone sodium 300mg and vecuronium $4 \mathrm{mg}$ IV. General anesthesia was maintained with $\mathrm{O}_{2} 33 \% / \mathrm{N}_{2} \mathrm{O} 66 \%$ /halothane with IPPV, throughout the procedure.

Intraoperative findings: a deep cut wound about $18 \mathrm{cms}$ in the anterior part of neck extending from Right sternocledomastoid to Left sternocledomastoid was seen. and bilateral external jugular veins were cut. However carotids, internal jugular veins and esophagus were narrowly missed. Betadine hydrogen peroxide wash was given and a new trachestoma was created at $2^{\text {nd }} / 3^{\text {rdtracheal }}$ rings and 
tracheostomy tube was introduced to it and simultaneously the endotracheal tube which was secured previously was withdrawn. Transected trachea was sutured with prolene. Thyroid cartilage, sternocledomastoid and strap muscles were sutured. Toward the end of the procedure,patient regained spontaneous ventilation, was reversed with neostigmine and glycopyrolate. After confirming good muscle power,and adequate tidal volume, patient was shifted to ICU for further monitoring.In the ICU patient was conscious, well oriented, his vitals were, BP:120/70mmHg, respiratory rate was $14 / \mathrm{min}, \mathrm{Spo}_{2} 100 \%$.Patient received supplemental oxygen $6 \mathrm{~L} / \mathrm{min}$ through $\mathrm{T}$-piece, iv fluids and iv analgesics.

His postoperative recovery was uneventful. On $10^{\text {th }}$ postoperative day tracheostomy tube was removed. No respiratory distress was noticed. Phonation, swallowing and breathing were normal. After having consulted with psychiatrist he was discharged on $17^{\text {th }}$ postoperative day.

DISCUSSION: Cut throat injuries pose a great challenge because, multiple vital structures are vulnerable to injuries in the small confined unprotected area. ${ }^{7}$ These injuries are a unique form of trauma that is potentially devastating and associated with substantial emotional, physical and financial burden on community and hospital resources. ${ }^{8}$ They cause profound morbidity due to prolonged hospitalization, high cost of health care, loss of productivity and reduced quality of life and above all death. 8,9

In such injuries we should keep in mind the possibility of injury to vital structures, like larynx, trachea, esophagus, major neck vessels, nerve roots and spinal cord. A good knowledge of nature and type of cutthroat wounds allows the clinician to treat these patients better. They require a multidisciplinary approach involving the anaesthesiologist, ENT surgeon, and a psychiatrist and the prognosis will be better if patients present early to the hospital and are given prompt attention. ${ }^{10}$

Our present case study was a self-inflicted cut throat injury by a middle aged male patient. Many previous studies have shown male predominance. Male predominance is attributable to their active participation in risk taking behaviors and their frequent involvement in interpersonal violence. ${ }^{10}$ In our case, as the larynx was exposed securing the airway as early as possible was done by the anaesthesiologist. There by breathing was restored, and further aspiration was prevented.

To prevent further blood loss wound exploration was planned immediately and hemostasis was attained. Tracheostomy, laryngeal and hypopharyngeal repair were performed. Similar modality of treatment was reported by other authors. As such injuries require interdisciplinary approach; there was involment of anaesthesiologist, ENT surgeon immediately. As suicide is a sign of underlying mental illness and there is possibility of a second attempt, our patient was referred to a psychiatrist postoperatively. Timely management might have reduced mortality and morbidity in our case.

\section{REFERENCES:}

1. Hasukura H, Fukushima H, Yonemura I, Ota M. A rare suicidal case of a ten year old child stabbing himself in the throat. J. Forensic sci.1985; 30 (4):1269-71.

2. Kendall JL, Anglin D, Demetriades D. Penetrating neck trauma, Emerg. Med Clin North Am 1998, 16:85-105.

3. Modi JP, Pandy AS. Modis Medical Jurisprudence and Toxicology. 20th ed. In: Modi NJ, editor. Bombay, India; Lexisnexis Buerworths Wadhwa 1977. p. 256-75. 
4. Ezeanolue B. Management of the upper airway in severe cut throat injuries. Afr J Med Med Sci 2001, 30 (3): 233-5.

5. Venkatachalam SG, Palaniswamy Selvaraj DA, Rangarajan M, Mani K, Palanivelu C. An unusual case of penetrating tracheal ("cut throat") injury due to chain snatching: the ideal airway management. Indian J Crit Care Med 2007, 11(3):151-4.

6. Herzog M, Hoppe F, Baier G, Dieler R. Injuries of the head and neck in suicidal intention. Laryngorhinootologie 2005, 84 (3): 176-81.

7. Manilal A, Khorshed ABM, Talukdar DC, Sarder RMA, Fakir AT, Hossain M. Cut throat injury: review of 67 cases. Bangladesh J Otorhinolaryngol.2011, 17:5-13.

8. Krug EG, Sharma GK, Lozano R. The global burden of injuries. Am J Publ Health 2000; 90: 523526.

9. Bumpous JM, Whitt PG, Gangel TM, Mc Clone S D. Penetrating injuries of the visceral compartment of the neck. Am J Otolaryngol.2000, 21:190-194.

10. Gilyoma et al. BMC Emergency Medicine 2014, 14:1 Page 3 of 7. http://www.biomedcentral.com/1471-227X/14/1.

\section{AUTHORS:}

1. Shruthi Jayaram

2. Bhagyashree Amingad

\section{PARTICULARS OF CONTRIBUTORS:}

1. Assistant Professor, Department of Anaesthesiology, Hassan Institute of Medical Sciences.

2. Assistant Professor, Department of Anaesthesiology, Hassan Institute of Medical Sciences.

\section{NAME ADDRESS EMAIL ID OF THE} CORRESPONDING AUTHOR:

Dr. Shruthi Jayaram,

Door No. 36, Doctors Quarters,

Hassan Institute of Medical Sciences,

Hassan-573201.

Email: shruthijayaram08@gamil.com

Date of Submission: 30/10/2014.

Date of Peer Review: 31/10/2014.

Date of Acceptance: 07/11/2014.

Date of Publishing: 10/11/2014. 